\title{
Development and Standardization of the Gratitude Scale
}

\author{
Mohammad Anas \\ Research Scholar, Department of Psychology, Aligarh Muslim University, \\ Aligarh-202002 (India) \\ Akbar Husain \\ Professor, Department of Psychology, Aligarh Muslim University, \\ Aligarh-202002 (India) \\ profakbar6@gmail.com \\ Shah Mohd. Khan \\ Associate Professor, Department of Psychology, Aligarh Muslim University, \\ Aligarh-202002 (India) - Corresponding Author (khandrsm@gmail.com) \\ Asiya Aijaz \\ Professor, Department of Psychology, Aligarh Muslim University, Aligarh-202002
}

\begin{abstract}
The Gratitude Scale (GS) developed by the authors was administered to 456 adults to determine the psychometric characteristics i.e. reliability and validity. Cronbach's Alpha of the scale was found 0.91 . Content validity of the scale was verified by some experts, academicians, and professionals. For testing multicollinearity and singularity 'Determinant' of the R-matrix was estimated and it was greater than 0.00001 . The items having factor loading greater than or equal to 0.40 were selected. Total 26 items with five dimensions emerged through Exploratory Factor Analysis explaining 58.14\% of the variance, which provided the evidence of factorial/construct validity of the scale. The scale can be used for research and human resource development programs in school/university and organizations.
\end{abstract}

Keywords: Gratitude, content validity, Factor analysis, Multicollinearity, R-Matrix

\section{Introduction}

The gratitude has been derived from Latin word 'gratita' which means have to do with kindheartedness, generousness, assistance, the beauty of benevolent and in receipt of, or getting something for nothing (Pruyser, 1976, p. 69). Gratitude has been traditionally emerging in the 
context of a religious context. Although the various life experiences can elicit feelings of gratitude, prototypically gratitude stems from the perception that one has taken a gift or return from another person. Throughout the history the gratitude has been itself has some meaning in the different context or different religions. The idea of gratitude was a vital theme taken up by philosophers since varied like Thomas Aquinas, Thomas Hobbes, Samuel Pufendorf, and Adam Smith and remain a significant idea throughout the Middle Ages (see Dunn, 1946; Galloway, 1994; Tronto, 1999). Bonhoeffer (1967) remarked, "In everyday life, we only just realize that we obtain a great agreement more than we give and that it is only with gratitude that life becomes rich" (p. 370).

Numerous experts have recognized the social, physical, and psychological benefits associated with gratitude. The previous study suggests that these benefits are accessible to most everyone who practices gratitude, even in the middle of complexity, such as older adults confronting death, women with breast cancer, and people coping with a chronic muscular disease. Gratitude brings us happiness: one study conducted by Emmons and Lyubomirsky's work on gratitude has proven to be one of the most reliable techniques for increasing happiness and life satisfaction. Gratitude enhances feelings of optimism, joy, pleasure, enthusiasm, and other positive emotions also reduce anxiety and depression. The gratitude has so many meaning by various thinkers in their context; some thinkers said that the gratitude is used in the context of Thanksgiving and some used in the context of a tendency of grateful attitude toward others.

From a positive psychology perspective, gratitude is a virtue with roots in early attachment experiences. In the traditional religious families, it was relatively common. It was cultivated by parents during childhood. Currently, gratitude is not very much emphasized in contemporary culture. In fact, gratitude is a social phenomenon.

Gratitude has been most important aspect of human beings social and emotional lives. In recent researches, the gratitude has been one of the most important aspects of the experiencing and expression of gratitude in the moral behavior. McCullough, Kilpartrick, Emmons, and Larson (2001) have described three aspects of the gratitude as a moral barometer, moral motive, moral 
Journal of Educational, Health and Community Psychology

Vol 5, No 3, 2016.

Mohammad Anas, Akbar Husain, Shah M. Khan, Asiya Aijaz

reinforce. Early researches have been conducted on the different aspects of the social, developmental and evolutionary psychology to support this conceptualization. Emmons and McCullough (2003) conducted a study on the common population in which they found that people who are doing the gratitude on the everyday basis feel more optimistic and have fewer physical symptoms, felt better about lives as a whole, as compared to those people who have life felt like a daily hassle.

\section{Gratitude: Concept and Definitions}

Gratitude is associated with thanks and habit among some people (Solomon, 1995). It is possible that regard the experience and expression of gratitude as evidence of helplessness and weakness, which may threaten their masculine and social status (Levant \& Kopecky, 1995). Consequently, men may adopt an avoidance orientation toward gratitude, showing a preference to conceal rather than express it. That would provide as a type of self-defending mechanism from contact with unwanted negative emotional experiences or unpleasant social consequences. Ironically, this avoidance orientation may cause even greater disruption to psychological and social wellbeing. This orientation is expected to diverge from women who, on middling, are more familiar with emotions and behaviors with the aim of creating and sustaining meaningful social relationships.

Kant (1797/1964) defines gratitude as "honoring a person because of kindness he has done us" (p. 123). Emmons and McCullough (2003) define gratitude as "a felt sense of wonder, thankfulness, and appreciation for life. It can be expressed to others, as well as to impersonal (nature) or non-human sources (God, animal, the Cosmos)" (p.377). Gratitude has been defined as "a sense of thankfulness and joy in response to receiving a gift, whether the gift is a tangible benefit from a specific other or a moment of peaceful bliss evoked by natural beauty" (Emmons, 2004).

Gratitude may be defined as "a sense of thankfulness and joy in response to receiving a gift, whether the gift is a tangible benefit from a specific other or a moment of peaceful bliss evoked by natural beauty" (Peterson \& Seligman, 2004, p. 554). 


\section{Significance of Gratitude in Daily Life}

The gratitude is one important aspect of higher education which is helpful in enhancing motivation, well-being, and academic learning process is still an unexplored area. It needs to be focused on how the meaning of the term 'gratitude' is to be understood in a customary academic context. Simmel (1996) argues that gratitude is the most vital interrelated element for society. This concept has important implication for teaching and learning community who are constantly looking to receive without any motivation to "give back" out of a sense of gratitude. Heidegger (1968) has stated that the origin of term "thinking" is the "thanks owed for being." Does he expand this notion by saying that-"How can we give thanks for this endowment, the gift of being able to think what is most thought-provoking, more fittingly than by giving though to most thought provoking? The supreme thanks, then would be thinking? And the most profound thanklessness, thoughtlessness?" he emphasized on a circular relationship between thinking and gratitude. The more one thinks with gratitude; the more one is truly thinking. Similarly, the more one can bring one's whole self to thinking process the more one is expressing gratitude for the ability to think.

\section{Aim of the study}

The main aim of the present study is to standardize a gratitude scale.

\section{Development of scale}

In the first stage experts in the field of psychology were contacted and the objective of developing the scale was explained to them. With the experts' opinion, five dimensions of Gratitude scale were finalized, they are:

1. Desirable Aspect of Life.

2. Reciprocal Nature of Gratitude.

3. Gratitude Towards others.

4. Experience Gratitude.

5. Gratitude- Related Activities. 
Journal of Educational, Health and Community Psychology

\section{Operational Definition of Gratitude and its Dimensions}

Gratitude is defined as the process through which the person has the tendency to show the positive attitude towards life by reciprocity or exchanging the emotion, and these emotions are helpful in service to humanity, the person feels some experience of gratitude by involving in gratitude-related activities.

\section{Dimensions of Gratitude}

Desirable Aspect of Life: The situation in which the person can elicit the gratitude toward those persons who have the desirable outcome for their action or give the reinforcement after achieving success.

Reciprocal Nature of Gratitude: It is the exchange of positive emotion. Someone performs an act of gratitude for another person, and in turn, that person may be encouraged to do something good for that person, or persist in kindness for an unfamiliar person.

Gratitude Toward others: Gratitude can be expressed by promoting the activity of humanity, and to serve the needy persons.

Experience Gratitude: A person experiences gratitude after getting the reward and success and also shows gratitude toward God after reading the scriptures. The higher gratitude than the higher experience.

Gratitude-Related Activities: It is aimed at the maintenance of righteousness and order. A person can express gratitude to involve in the worship of their religious faith.

\section{First Draft of the Scale and Item Analysis}

In the first stage, 32 items with 5-point Likert-type responses, viz., 'Strongly disagree,' 'Disagree,' 'Neutral,' 'Agree,' 'Strongly agree' were obtained. This scale was administered to a representative sample of 200 male and female adults.

After scoring the items of each testee, the scores were arranged in descending order (highest scoring to the lowest). Two separate groups, one of $27 \%$ from the highest scoring and other of $27 \%$ from the lowest scoring were made. Inter-correlation matrix was examined to overcome 
existence of multicollinearity and singularity in the scale. After analysis, 06 items having the multicollinearity and singularity were rejected and the final draft of the scale comprised 26 items.

Table 1

Dimension and No. of Items

\begin{tabular}{lllc}
\hline Dimensions & Items & No. of Items \\
\hline 1. & Desirable Aspects of Life & $21,19,23,22,24,20,18,25$ & 08 \\
2. & Reciprocal nature of Gratitude & $12,13,10,11,14,26$ & 06 \\
3. & Gratitude towards others & $7,6,8,9,5$ & 05 \\
4. & Experience Gratitude & $15,16,17,3$ & 04 \\
5. & Gratitude-related Activities & $2,1,4$ & 03 \\
Total & & & 26 \\
\hline
\end{tabular}

Table 2

Scoring System

\begin{tabular}{lllll}
\hline Strongly disagree & Disagree & Neutral & Agree & Strongly Agree \\
\hline 1 & 2 & 3 & 4 & 5 \\
\hline
\end{tabular}

\section{Standardization of the Scale}

The final draft with 26 items was administered to a sample of 456 adults selected from urban areas of district Aligarh. 456 adults were further divided into male and female. The male adults were 226, and female adults were 230. In respect to religion, the sample of Muslim was 238 and Hindu was 218. The total score of the scale varies from 26 to 130 and can be inferred as higher the score higher the gratitude.

The mean age of the adults participated in the development of scale was 31.20 years with 21 years as minimum and 40 years as a maximum. 


\section{Instructions}

Instructions for administration of the scale were printed on the first page of the scale. The scale can be administered individually or in a group (not more than 30 subjects at a time). The subjects were assured that their responses will not be disclosed but will be used for the research purpose only. Read each item carefully and give your responses candidly.

\section{Reliability}

The considerations of reliability and validity typically are viewed as essential elements for determining the quality of any standardized test. However, professional and practitioner associations frequently have placed these concerns within broader contexts when developing standards and making overall judgments about the quality of any standardized test as a whole within a given context. Cronbach alpha was used for determining the internal consistency reliability. Cronbach's Alpha was found 0.91 which is significant at 0.01 level. The internal consistency of the scale is quite high, and this gives a support that the scale has excellent reliability (George \& Mallery, 2003).

Table 3

Descriptive statistics of Items Scale and Cronbach's Alpha

\begin{tabular}{lcccccccc}
\hline Item & \multicolumn{3}{c}{ Descriptive statistics for item } & \multicolumn{3}{c}{ Descriptive statistics for scale } \\
\cline { 2 - 8 } No. & Range & Mean & Median & Variance & SD & Scale Means & *Corrected & Cronbach's \\
\hline & & & & & & if item & Item-Total & Alpha if Item \\
& & & & & & Deleted & Correlation & Deleted \\
\cline { 5 - 8 } & & & & & & & & \\
GS1 & 4 & 4.02 & 4.00 & .79 & .89 & 101.66 & .43 & .91 \\
GS2 & 4 & 3.67 & 4.00 & 1.00 & 1.00 & 102.01 & .45 & .91 \\
GS3 & 4 & 3.97 & 4.00 & .98 & .99 & 101.71 & .49 & .91 \\
GS4 & 4 & 4.00 & 4.00 & .77 & .87 & 101.68 & .44 & .91 \\
GS5 & 4 & 4.14 & 4.00 & .84 & .91 & 101.54 & .55 & .91
\end{tabular}


Journal of Educational, Health and Community Psychology

Vol 5, No 3, 2016. Mohammad Anas, Akbar Husain, Shah M. Khan, Asiya Aijaz

\begin{tabular}{|c|c|c|c|c|c|c|c|c|}
\hline \multirow{2}{*}{$\begin{array}{l}\text { Item } \\
\text { No. }\end{array}$} & \multicolumn{5}{|c|}{ Descriptive statistics for item } & \multicolumn{3}{|c|}{ Descriptive statistics for scale } \\
\hline & Range & Mean & Median & Variance & $\mathrm{SD}$ & Scale Means & $*$ Corrected & Cronbach's \\
\hline & & & & & & if item & Item-Total & Alpha if Item \\
\hline & & & & & & Deleted & Correlation & Deleted \\
\hline GS6 & 4 & 4.07 & 4.00 & .78 & .88 & 101.61 & .51 & .91 \\
\hline GS7 & 4 & 4.09 & 4.00 & .81 & .90 & 101.59 & .54 & .91 \\
\hline GS8 & 4 & 4.24 & 4.00 & .66 & .81 & 101.44 & .53 & .91 \\
\hline GS9 & 4 & 4.09 & 4.00 & .71 & .84 & 101.59 & .57 & .91 \\
\hline GS10 & 4 & 4.27 & 4.00 & .62 & .79 & 101.41 & .51 & .91 \\
\hline GS11 & 4 & 4.19 & 4.00 & .69 & .83 & 101.49 & .53 & .91 \\
\hline GS12 & 4 & 4.04 & 4.00 & .68 & .82 & 101.64 & .49 & .91 \\
\hline GS13 & 4 & 4.02 & 4.00 & .68 & .82 & 101.66 & .49 & .91 \\
\hline GS14 & 4 & 4.01 & 4.00 & .76 & .87 & 101.67 & .56 & .91 \\
\hline GS15 & 4 & 3.98 & 4.00 & .83 & .91 & 101.70 & .57 & .91 \\
\hline GS16 & 4 & 4.10 & 4.00 & .76 & .87 & 101.58 & .64 & .91 \\
\hline GS17 & 4 & 3.86 & 4.00 & 1.11 & 1.05 & 101.82 & .54 & .91 \\
\hline GS18 & 4 & 3.89 & 4.00 & 1.07 & 1.03 & 101.79 & .48 & .91 \\
\hline GS19 & 4 & 4.18 & 4.00 & .79 & .88 & 101.50 & .50 & .91 \\
\hline GS20 & 4 & 4.11 & 4.00 & .74 & .86 & 101.57 & .49 & .91 \\
\hline GS21 & 4 & 4.40 & 5.00 & .61 & .78 & 101.28 & .46 & .91 \\
\hline GS22 & 4 & 4.06 & 4.00 & .87 & .93 & 101.62 & .48 & .91 \\
\hline GS23 & 4 & 3.86 & 4.00 & .85 & .92 & 101.82 & .48 & .91 \\
\hline GS24 & 4 & 4.14 & 4.00 & .76 & .87 & 101.54 & .56 & .91 \\
\hline GS25 & 4 & 4.10 & 4.00 & .72 & .85 & 101.58 & .51 & .91 \\
\hline GS26 & 4 & 4.17 & 4.00 & .72 & .84 & 101.51 & .53 & .91 \\
\hline
\end{tabular}


Journal of Educational, Health and Community Psychology

Vol 5, No 3, 2016.

Mohammad Anas, Akbar Husain, Shah M. Khan, Asiya Aijaz

Table 4

Descriptive statistics of Scale and Reliability (Cronbach's alpha)

\begin{tabular}{lccccc}
\hline Statistics scale & Mean & Variance & Std. Deviation & Alpha & No. of Items \\
\hline & & & Coefficient & \\
\cline { 3 - 5 } & & & 0.91 & 26 \\
\hline
\end{tabular}

\section{Validity}

Content (Face and logical) validity of the scale was verified by some experts and academicians. There are various methods to establish construct validity of the tool. Factor analysis with varimax rotation was used to establish the construct validity of the tool. Data screening was carried out to overcome existence of multicollinearity and singularity in the scale. For testing multicollinearity and singularity 'Determinant' of the R-matrix was estimated and it was greater than 0.00001. Sampling adequacy was also carried out and found to be greater than 0.50 as required in both cases.

For using a more structured method, Exploratory Factor Analysis was carried out, and five factors emerged in the analysis. The items having factor loading greater than or equal to 0.40 were selected.

The percent of variance accounted by factors varies from 7.73 to $13.02 \%$. In summing up, all five factors explained $54.18 \%$ of the total variance. The factorial validity of the scale was found very high. The factor loadings, percent of variance and cumulative percent of variance for each dimension are also shown. 
Journal of Educational, Health and Community Psychology

Vol 5, No 3, 2016.

Mohammad Anas, Akbar Husain, Shah M. Khan, Asiya Aijaz

Table 5

Factor structure of the Gratitude Scale (GS)

\begin{tabular}{|c|c|c|c|c|c|}
\hline \multirow[t]{2}{*}{ Item No. } & \multicolumn{5}{|c|}{ Factor Loadings } \\
\hline & $\mathrm{I}$ & II & III & IV & $\mathrm{V}$ \\
\hline GS21 & .660 & & & & \\
\hline GS19 & .649 & & & & \\
\hline GS23 & .649 & & & & \\
\hline GS22 & .635 & \multicolumn{4}{|c|}{ Desirable aspects of gratitude } \\
\hline GS24 & .601 & & & & \\
\hline GS20 & .486 & & & & \\
\hline GS18 & .479 & & & & \\
\hline GS25 & .471 & & & & \\
\hline GS12 & & (729). & & & \\
\hline GS13 & & .685 & & & \\
\hline GS10 & & .625 & & & \\
\hline GS11 & & .542 & \multicolumn{3}{|c|}{ Reciprocal Nature of gratitude } \\
\hline GS14 & & .472 & & & \\
\hline GS26 & & .729 & & & \\
\hline GS7 & & & $.777)$ & & \\
\hline GS6 & & & .759 & & \\
\hline GS8 & & & .689 & & \\
\hline GS9 & & & .490 & \multicolumn{2}{|l|}{ Gratitude towards other } \\
\hline GS5 & & & .486 & & \\
\hline GS15 & & & & .671 & \\
\hline GS16 & & & & .642 & \\
\hline GS17 & & \multirow{2}{*}{\multicolumn{2}{|c|}{ Experience Gratitude }} & .626 & \\
\hline GS3 & & & & .613 & \\
\hline GS2 & & & \multirow{3}{*}{\multicolumn{2}{|c|}{ Gratitude Related Activity }} & $\int .690$ \\
\hline GS1 & & & & & .678 \\
\hline GS4 & & & & & .482 \\
\hline PCT of Var. & 13.02 & 12.53 & 10.77 & 10.15 & 7.73 \\
\hline Cum. PCT of & 13.02 & 25.54 & 36.30 & 46.46 & 54.18 \\
\hline Var. & & & & & \\
\hline
\end{tabular}

Inter- Factorial Validity

The inter-factorial validity of the scale was calculated to confirm all factors as correlated to each other and measuring the same construct. The Cronbach's Alpha of each factor has also been calculated and shown in Table 6. 
Journal of Educational, Health and Community Psychology

Vol 5, No 3, 2016.

Mohammad Anas, Akbar Husain, Shah M. Khan, Asiya Aijaz

Table 6

Dimension-wise Inter-factorial Validity and Cronbach's Alpha.

\begin{tabular}{lcccccc}
\hline Dimensions & Reliability $(\alpha)$ & \multicolumn{5}{c}{ Factors } \\
\cline { 3 - 7 } & & F1 & F2 & F3 & F4 & F5 \\
\hline Desirable aspects of life & 0.811 & 1.00 & & & & \\
Reciprocity Nature of Gratitude & 0.783 & .591 & 1.00 & & & \\
Gratitude towards others & 0.818 & .464 & .591 & 1.00 & & \\
Experience Gratitude & 0.749 & .618 & .573 & .502 & 1.00 & \\
Gratitude Related Activity & 0.587 & .436 & .431 & .531 & .522 & 1.00 \\
\hline
\end{tabular}

$r=0.10 p<0.05 ; r=13 p<0.01 ; r=16 p<0.001$ (two tailed)

F1 = Desirable aspects of life, F2= Reciprocity Nature of Gratitude, F3= Gratitude towards others, F4= Experience Gratitude, F5= Gratitude Related Activity

Inter-factorial correlations indicate that all the factors are significantly correlated with each other and measuring the same construct. The Cronbach's Alpha for factors varying from 0.587 to 0.818 , which is satisfactory.

\section{Discussion}

The objective of this study was to determine the psychometric characteristics, i.e. reliability and validity of the Gratitude scale developed for Adults Indian population (Hindus and Muslims). The analysis of the internal consistency and item correlations demonstrated the adequate reliability of the gratitude scale. Using the Exploratory Factor Analysis, we determined the internal factorial/construct validity of the scale, which is highly satisfactory. 
Journal of Educational, Health and Community Psychology

\section{Conclusions}

Following findings of the development and standardization of the Gratitude Scale can be drawn. First, five factors, namely, Desirable aspects of life, Reciprocity Nature of Gratitude, Gratitude towards others, Experience Gratitude and Gratitude Related Activity emerged as very natural in measuring the level of gratitude in adult Indian population (Hindu \& Muslim). Second, reliability and validity coefficients based on 456 adults confirmed that Gratitude scale has quite satisfactory psychometric characteristics.

\section{Suggestions}

Future research needs to understand the dynamic nature of gratitude. There is a need to expand evidence-based approaches' for humanizing the situation of spiritual peace, altruistic love, benevolence or kindness that are essential to enduring gratitude behavior. Research shows that for well-being and happiness an individual needs to be emotionally stable, socially kinder, more optimistic, goal achievement and full of longevity. All these variables need to be examined empirically. Future research should examine the relationship of gratitude with various other aspects of psychological behavior. Gratitude is also understood in the light of spirituality and religion. It needs to be searched out why gratitude is important for the positive aspect of life.

\section{Implications}

Gratitude is a critical element in the light of pro-social behavior through which the people take responsibility for the positivity in their life and also helpful nature towards God and other aspects of life, and this scale can be used to explore and address in research and human resource development programs. Gratitude helps us in improving the well-being and in resolving the interpersonal conflicts. The intervention programs at the college/university levels can be organized for measuring the gratitude and counseling through professionals to uphold it to a satisfactory level, in turn, which will help to uphold high conformity among adults.

As we know, a grateful person would be characterized by the tendency to appreciate simple pleasure. Simple pleasures refer to those pleasures in life that are readily available to the most 
Journal of Educational, Health and Community Psychology

Vol 5, No 3, 2016.

Mohammad Anas, Akbar Husain, Shah M. Khan, Asiya Aijaz

people. If gratitude inculcated at college/university levels, it is expected that grateful adult should realize the importance of practicing, experiencing and expressing gratitude to society at large and resulting in building the nation.

\section{REFERENCES}

Bonhoeffer, D. (1967). Letters and papers from prison (E. Bethge, Ed.). New York: Macmillan.

Ciarrochi, J., Hynes, K., \& Crittenden, N. (2005). Can men do better if they try harder: Sex and motivational effects on emotional awareness? Cognition and Emotion, 19, 133-141.

Dunn, E. C. (1946). The concept of ingratitude in Renaissance English moral philosophy. Washington, DC: Catholic University of America Press.

Emmons, R. A. (2004). Gratitude. In M E. P. Seligman \& C. Peterson (Eds.), The VIA taxonomy of human strength and virtues. New York: Oxford University Press.

Emmons, R. A., \& McCullough, M. E. (2003). Counting blessings versus burdens: An experimental investigation of gratitude and subjective well-being in daily life. Journal of Personality and Social Psychology, 84, 377-389.

Galloway, A. (1994). The making of a social ethic in late-medieval England: From gratitude to "Kindness." Journal of the History of Ideas, 55(3), 365-383.

Heidegger, M. (1968). What is Called Thinking? Translated by F. Wick \& J. Gray. New York: Harper \& Row.

Kant, I. (1964). The metaphysical principles of virtue: Part II of The metaphysics of morals (J. Ellington, Trans.). Indianapolis, IN: Bobbs-Merrill. (Original work published 1797).

Levant, R. F., \& Kopecky, G. (1995). Masculinity, reconstructed. New York: Dutton.

McCullough, M. E., Kilpatrick, S. D., Emmons, R.A., \& Larson, D.B. (2001). Is gratitude a moral affect? Psychological Bulletin, 127(2), 249-266.

Naito, T., Wangan, J., \& Tani, M. (2005). Gratitude in university students in Japan and Thailand. Journal of Cross-Cultural Psychology, 36, 247-263.

Peterson, C., \& Seligman, M. E. P. (2004). Character Strengths and virtues: A Handbook and Classification. New York, Oxford University Press. 
Pruyser, P. W. (1976). The minister as diagnostician: Personal problems in pastoral perspective. Philadelphia: Westminster Press.

Simmel, G. (1996). Faithfulness and Gratitude. In A. Komter (ed.). The Gift: An interdisciplinary perspective. Amsterdam: Amsterdam University Press.

Simon, R. W., \& Nath, L. E. (2004). Gender and emotion in the united states; Do men and women differ in self-reports of feelings and expressive behavior? American Journal of Sociology, 109, 1137-1176.

Solomon, R.C. (1995). The cross-cultural comparison of emotion. In J. Marks \& R.T. Ames (Eds.), Emotions in Asian thought (pp.253-294). Albany: SUNY Press.

Tronto, J. C. (1999, September). Politics and gratitude: Revisiting Hobbes's "social virtues." Paper presented at the annual meeting of the American Political Science Association, Atlanta, GA. 